\title{
National Ignition Campaign Hohlraum Energetics
}

N. B. Meezan, L. J. Atherton, D. A. Callahan, E. L. Dewald, S. N. Dixit, E. G. Dzenitis, M. J. Edwards, C. A. Haynam, D. E. Hinkel, O. S. Jones, O. Landen, R. A. London, P. A. Michel, J. D. Moody, J. L. Milovich, M. B. Schneider, C. A. Thomas, R. P. J. Town, A. L. Warrick, S. V. Weber, K. Widmann, S. H. Glenzer, L. J. Suter, B. J. MacGowan, J. L. Kline, G. A. Kyrala, A. Nikroo

November 23, 2009

Physics of Plasmas 
This document was prepared as an account of work sponsored by an agency of the United States government. Neither the United States government nor Lawrence Livermore National Security, LLC, nor any of their employees makes any warranty, expressed or implied, or assumes any legal liability or responsibility for the accuracy, completeness, or usefulness of any information, apparatus, product, or process disclosed, or represents that its use would not infringe privately owned rights. Reference herein to any specific commercial product, process, or service by trade name, trademark, manufacturer, or otherwise does not necessarily constitute or imply its endorsement, recommendation, or favoring by the United States government or Lawrence Livermore National Security, LLC. The views and opinions of authors expressed herein do not necessarily state or reflect those of the United States government or Lawrence Livermore National Security, LLC, and shall not be used for advertising or product endorsement purposes. 


\section{National Ignition Campaign hohlraum energetics}

N. B. Meezan, ${ }^{1,}$ a) L. J. Atherton, ${ }^{1}$ D. A. Callahan, ${ }^{1}$ E. L. Dewald, ${ }^{1}$ S. Dixit, ${ }^{1}$ E. G.

Dzenitis, ${ }^{1}$ M. J. Edwards, ${ }^{1}$ C. A. Haynam, ${ }^{1}$ D. E. Hinkel, ${ }^{1}$ O. S. Jones, ${ }^{1}$ O. Landen, ${ }^{1}$ R. A. London, ${ }^{1}$ P. A. Michel, ${ }^{1}$ J. D. Moody, ${ }^{1}$ J. L. Milovich, ${ }^{1}$ M B. Schneider, ${ }^{1}$ C. A. Thomas, ${ }^{1}$ R. P. J. Town, ${ }^{1}$ A. L. Warrick, ${ }^{1}$ S. V. Weber, ${ }^{1}$ K. Widmann, ${ }^{1}$ S. H. Glenzer, ${ }^{1}$

L. J. Suter, ${ }^{1}$ B. J. MacGowan, ${ }^{1}$ J. L. Kline, ${ }^{2}$ G. A. Kyrala, ${ }^{2}$ and A. Nikroo ${ }^{3}$

1) Lawrence Livermore National Laboratory, P.O. Box 808, Livermore, CA, 94551-0808

2) Los Alamos National Laboratory, Los Alamos, NM, 87545

3) General Atomics, P.O. Box 85608, San Diego, CA, 93286-5608 
The first series of experiments on the National Ignition Facility (NIF) [E. I. Moses, R. N. Boyd, B. A. Remington, C. J. Keane, and R. Al-Ayat, "The National Ignition Facility: ushering in a new age for high energy density science," Phys. Plasmas 16, 041006 (2009)] tested ignition hohlraum "energetics," a term described by four broad goals:

1. Measurement of laser absorption by the hohlraum

2. Measurement of the x-ray radiation flux $\left(T_{R A D}^{4}\right)$ on the surrogate ignition capsule

3. Quantitative understanding of the laser absorption and resultant x-ray flux

4. Determining whether initial hohlraum performance is consistent with requirements for ignition.

This paper summarizes the status of NIF hohlraum energetics experiments. The hohlraum targets and experimental design are described, as well as the results of the initial experiments. The data demonstrate low backscattered energy $(<10 \%)$ for hohlraums filled with helium gas. A discussion of our current understanding of NIF hohlraum x-ray drive follows, including an overview of the computational tools, i.e., radiation-hydrodynamics codes, that have been used to design the hohlraums. The performance of the codes is compared to x-ray drive and capsule implosion data from the first NIF experiments. These results bode well for future NIF ignition hohlraum experiments.

PACS numbers: 52.38.Bv,52.38.Ph,52.57.Bc

a)Electronic mail: meezan1@llnl.gov 


\section{INTRODUCTION}

The National Ignition Facility (NIF) ${ }^{1}$ is designed to achieve fusion ignition using the inertial confinement fusion (ICF) scheme ${ }^{2}$. Successful indirect drive ignition on the NIF requires driving the implosion capsule to high velocity $(370 \mu \mathrm{m} / \mathrm{ns})$ while keeping the cryogenic deuterium-tritium fuel layer at low entropy. The imploded core must be round at stagnation to minimize cooling of the central hot spot by the adjacent cold, dense fuel. These three implosion requirements of high velocity, low entropy, and round shape are met by tailoring the radiation environment in the laser-driven hohlraum. The multi-stepped radiation drive launches four shocks of precise timing and strength to minimize entropy addition to the cold fuel. The peak pulse of the drive accelerates the shell toward stagnation at the required velocity. Symmetric irradiation of the capsule is achieved by controlling the locations of the laser beam spots on the hohlraum walls and by adjusting the relative power deposited to the inner (equatorial) and outer (polar) spots.

The hohlraum must deliver the required drive and symmetry in the presence of laserplasma interactions (LPI) such as stimulated Raman backscatter (SRS), stimulated Brillouin backscatter (SBS), and crossed-beam interactions, which can reflect and redirect the laser light as it propagates through the hohlraum plasma. Reflection of laser light out of the hohlraum results in loss of x-ray drive on the capsule and potential loss of symmetry control. Redistribution of laser light inside the hohlraum via reabsorption of the reflected light also impacts symmetry control. The physics of crossed-beam LPI are described in greater detail by Michel et al. ${ }^{3,4}$.

The National Ignition Campaign hohlraum energetics experiments were designed to assess ignition hohlraum performance at laser energies below the 1.2 to $1.5 \mathrm{MJ}$ required for ignition. The goal of the campaign is to develop a hohlraum platform that can be scaled up to ignition energy-levels. A successful hohlraum platform must have low backscatter reflectivity $(R<10 \%)$ and must have $\mathrm{x}$-ray drive consistent with ignition requirements. This paper

describes in detail the NIF experimental campaign that demonstrates these goals ${ }^{5}$. The paper focuses on global energetics: laser backscatter, x-ray drive, and x-ray coupling to the capsule. We describe the experimental setup and target designs for the campaign, as well as the radiation-hydrodynamics codes used to design the targets. After describing the experimental results, we summarize the measured hohlraum performance and compare it 
to calculations. Finally, we describe the implications of the results to ignition hohlraum designs.

\section{EXPERIMENT DESIGN}

\section{A. Target diagnostics}

The goal of the hohlraum energetics experiments is to measure the net power deposited in the hohlraum and the distribution of power inside the hohlraum. A suite of optical and x-ray diagnostics have been fielded at the NIF to accomplish this. The NIF's 192 laser beams are grouped into 48 quads. The inner cone is comprised of 8 quads at $23.5^{\circ} 8$ quads at $30^{\circ}$ relative to the hohlraum axis of rotation. The outer cone is comprised of 16 quads at $44.5^{\circ} 16$ quads at $50^{\circ}$. The laser power incident on the hohlraum is measured using NIF's laser diagnostics: The power delivered by each quad is measured with $\pm 3 \%$ accuracy by a combination of fast diodes and calorimeters in the $1 \omega(1053 \mathrm{~nm})$ and $3 \omega(351 \mathrm{~nm})$ sections of the laser. The NIF laser beams are smoothed by continuous phase plates (CPP's), smoothing by spectral dispersion (SSD), and polarization smoothing (PS) .

The backscattered power reflected out of the hohlraum is measured directly on one $30^{\circ}$ inner cone quad and on one $50^{\circ}$ outer cone quad by a pair of diagnostic systems. The Full-Aperture Backscatter Station (FABS) measures the energy, power and spectrum of the SRS and SBS light reflected back into each of the four $f / 20$ final optics apertures in a quad. The Near Backscatter Imager (NBI) measures light scattered within a $\approx f / 4$ cone around the quad center ${ }^{7}$. Together with a pulsed-laser calibration system ${ }^{8}$, they are capable of measuring the backscattered quad on each of the diagnosed quads with $\pm 15-20 \%$ accuracy.

Two Static X-ray Imager (SXI) pinhole cameras image the laser-entrance holes (LEH's) of the hohlraum at a polar angle of $19^{\circ}$ to the hohlraum and target chamber axis ${ }^{9}$. The broad-band soft x-ray spectrometer DANTE measures the x-ray flux and spectrum emitted from the LEH at an angle of $37.5^{\circ}$ to the hohlraum axis. DANTE is an absolutely-calibrated, 18-channel filtered x-ray diode array that measures x-rays with photon energies ranging from $\epsilon=70 \mathrm{eV}$ to $\epsilon=10 \mathrm{keV}^{10}$. Using the response function of each channel, we can "unfold" the x-ray spectrum emitted by the hohlraum at each time in the data record ${ }^{11}$. Hard $\mathrm{x}$-rays $(\epsilon>20 \mathrm{keV})$ generated by hot electrons are detected by the filter-fluorescer array FFLEX. 
The FFLEX data are unfolded by assuming a two-temperature bremsstrahlung spectrum to produce a hot electron energy and characteristic temperature $E_{\text {hot }}$ and $T_{h o t}{ }^{12}$.

The final x-ray diagnostic fielded in the hohlraum energetics experiments is the Gated Xray Detector (GXD), a filtered x-ray pinhole snout mounted in front of a micro-channel platephosphor-CCD camera stack. The GXD takes four 200 ps-long time records of the imploding capsule self-emission. The GXD is pointed in the equatorial plane of the hohlraum, i.e., it views the capsule from the side of the hohlraum. The shape of the imploded core selfemission is a sensitive measure of the laser power distribution inside the hohlraum. The time of each diagnostic record was referenced to the start of the NIF laser pulse using the NIF cross-timing system. Thus, in addition to measuring the shape of the imploded core, the GXD also recorded the time of peak x-ray brightness, or "bang time," to an accuracy of $\pm 50 \mathrm{ps}$.

\section{B. Radiation hydrodynamics codes}

The energetics target and laser pulses were designed with the ICF codes LASNEX and HYDRA. LASNEX ${ }^{13}$ is a 2-D axisymmetric radiation hydrodynamics/multiphysics code that was largely validated during the NOVA Technical Contract ${ }^{2,14}$. HYDRA ${ }^{15}$ is a massively parallel 3-D radiation hydrodynamics/multiphysics code that is used for very large 2-D and 3-D problems. We also use HYDRA for less-demanding 2-D simulations, in much the same way as LASNEX.

Both codes are run with very similar physics models. For laser-driven hohlraums, we use the in-line non-local-thermodynamic-equilbrium (NLTE) atomic physics model XSN ${ }^{16,17}$ to generate multi-group emissivity and opacity data for the gold and gold-boron hohlraum wall. The quotidian equation of state $(\mathrm{QEOS})^{18}$ is used for hohlraum materials and gases at low temperature; at high temperature, the XSN NLTE equation of state is used. For capsule materials, we use more sophisticated LTE tabular opacities and equations of state. For consistency, we have kept the physics models, code settings, and grid resolution as close as possible to ignition hohlraum calculations ${ }^{19}$. We refer to this as the "point design model". 


\section{Target design}

The target design goal for the energetics target was to build a target with hohlraum performance and internal plasma conditions close to those of a $1.2 \mathrm{MJ}$ ignition hohlraum while operating at laser energy $E_{L} \approx 500-750 \mathrm{~kJ}$. We accomplished this with constantenergy-density scaling: All target dimensions are scaled down by a scale factor, $s$. The laser pulse time is also scaled down by $s$, and the laser power is scaled by $s^{2}$. The target mass and volume are reduced by $s^{3}$, as is the delivered laser energy, maintaining the energy density of the ignition hohlraum.

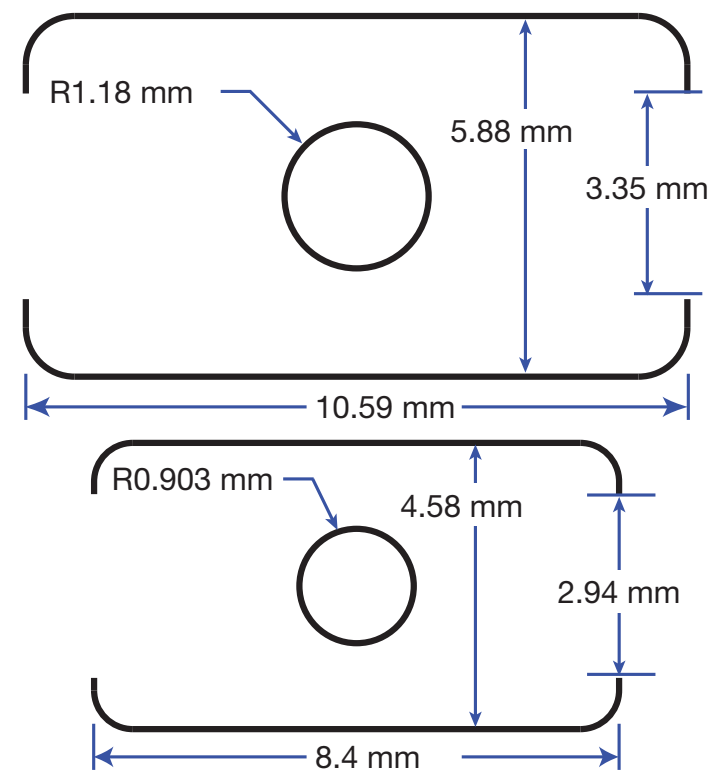

FIG. 1. Schematics of ignition (top) and subscale emulator hohlraums

The scale factor chosen was $s=0.78$, relative to a $1.2 \mathrm{MJ}, 285 \mathrm{eV}$ radiation temperature $\left(T_{R A D}\right)$ ignition hohlraum ${ }^{19,20}$. Schematics of the ignition and emulator hohlraums are shown in Fig. 1. The dimensions of this ignition hohlraum are very similar to those of a $1.4 \mathrm{MJ}$, $T_{R A D}=300 \mathrm{eV}_{\text {design }}{ }^{20}$, so the subscale hohlraum can serve as an emulator of either ignition design simply by changing the pulse shape. The ignition-scale and emulator-scale laser pulseshapes for both ignition designs are shown in Fig. 2. The $T_{R A D}=285 \mathrm{eV}$ emulator laser pulse has $520 \mathrm{~kJ}$ total energy, whereas the $T_{R A D}=300 \mathrm{eV}$ emulator pulse has $700-750 \mathrm{~kJ}$ total energy. For the smaller emulator hohlraums, we expect these pulses to result in lower radiation temperatures of $T_{R A D}=265 \mathrm{eV}$ and $T_{R A D}=285 \mathrm{eV}$, respectively. 


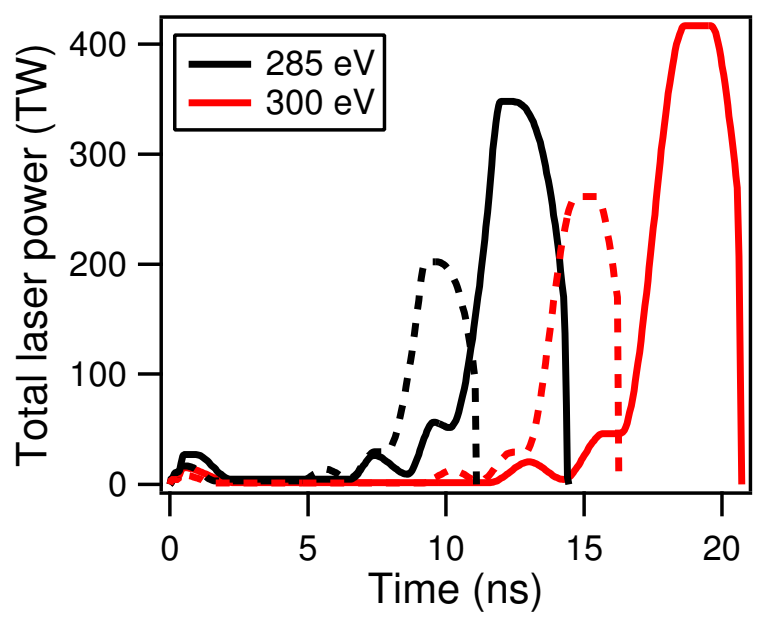

FIG. 2. (Color) Laser pulses for $T_{R A D}=285 \mathrm{eV}$ and $T_{R A D}=300 \mathrm{eV}$ ignition hohlraum designs (solid) and the laser pulses for their subscale emulator hohlraums (dash).

The emulator hohlraum contains all of the LPI-relevant materials of the $300 \mathrm{eV}$ ignition hohlraum with a plastic $(\mathrm{CH})$ capsule. The hohlraum wall consists of $30 \mu \mathrm{m}$ of gold with a $0.6 \mu \mathrm{m}$ liner of $60 \%$ gold, $40 \%$ boron on the inner surface. The boron co-sputtered into the gold increases the Landau damping of ion waves driven by $\mathrm{SBS}^{21,22}$. The hohlraum is filled with gas such that the electron density of the fully ionized gas is $4.5 \%$ of the critical density for $351 \mathrm{~nm}$ light, or $n_{e}=0.045 n_{c} \approx 4 \times 10^{20} \mathrm{~cm}^{-3}$. The entire target can be cryogenically cooled to $19 \mathrm{~K}$ so that the hohlraum can be filled with the same helium/hydrogen mixtures proposed for ignition hohlraums. The target can also be fielded at room temperature with a hydrocarbon gas-fill. The hohlraum laser-entrance holes are covered with $500 \mathrm{~nm}$-thick polyimide windows to hold the fielding gas. A $500 \mu \mathrm{m}$ diameter diagnostic-access hole is drilled in the equator of the hohlraum wall, facing the GXD camera. This allows an unimpeded view of the imploded core self-emission. The diagnostic hole is tamped with a $400 \mu \mathrm{m}$ diameter, $270 \mu \mathrm{m}$-thick plastic (polyetherimide) window to prevent the hole from closing under x-ray ablation.

The symmetry capsule, or "symcap," is a four-layer plastic $(\mathrm{CH})$ capsule with internal layers doped with $0.6 \%$ and $0.3 \%$ germanium (Figure 3 ). In an ignition capsule, the graded germanium dopant is used to taylor the Atwood number to reduce growth of the RayleighTaylor instability ${ }^{23}$. The capsule is manufactured using a glow-discharge polymer process ${ }^{24}$ and has a composition of $42.3 \%$ carbon, $57.2 \%$ hydrogen, and $0.5 \%$ oxygen. Unlike an 


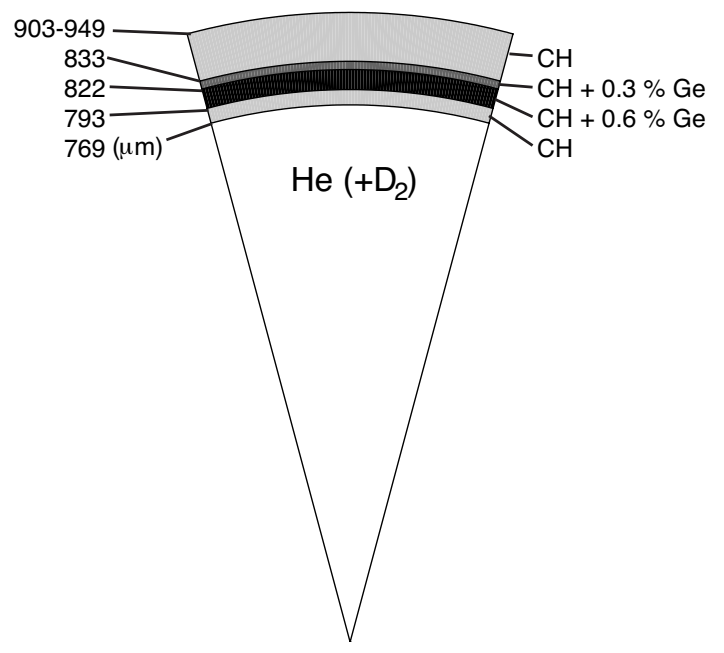

FIG. 3. Schematic of the four-layer symmetry capsule. For shots with the $11 \mathrm{~ns}, 500 \mathrm{~kJ}$ pulse, a $134 \mu \mathrm{m}$-thick shell was used. For some shots with the $16 \mathrm{~ns}, 700 \mathrm{~kJ}$ pulse, the outer layer was thicker, giving a total shell thickness of $155 \mu \mathrm{m}$ or $180 \mu \mathrm{m}$.

ignition capsule, a symcap does not have a cryogenic deuterium-tritium (DT) layer on its inner surface. The symcap is filled with $8.3 \mathrm{mg} / \mathrm{cm}^{3}$ of helium gas to generate x-rays at the time of peak convergence, or bang-time. The capsule fill density was chosen to give a convergence ratio of $\approx 10$, i.e., the capsule radius at bang-time approximately one-tenth of its initial radius (an ignition capsule has convergence ratio $\approx 30$ ). The shape of the imploded core is sensitive to low-mode irradiation asymmetries, but it is not very susceptible to the Rayleigh-Taylor instability. On some shots, the symcap is filled with $7-10 \%$ deuterium (by atom) to provide fusion neutrons for nuclear diagnostics testing.

\section{Hohlraum plasma conditions}

The key design requirement for the "plasma emulator" hohlraum is that it have similar plasma conditions to the ignition hohlraum in the regions where LPI occurs. This can be illustrated by a simplified expression of the linear gain for Raman or Brillouin backscatter:

$$
G=I \times L \times f\left(n_{e}, T_{e}, T_{i}, v, Z, A\right) .
$$

Here, the gain $G$ is the convective growth exponent, $I$ is the laser intensity, and $L$ is the plasma length. The function $f$ represents the instability spatial growth rate divided by the 
laser intensity ${ }^{25,26}$ and is a function of the laser wavelength and the plasma conditions. For SRS, $f$ depends on the electron density $n_{e}$ and temperature $T_{e}$. SBS growth depends on $n_{e}, T_{e}$, the ion temperature $T_{i}$, flow velocity $v$, and the plasma composition (represented by $Z$ and $A$ ). In Fig. 4, we compare plasma conditions from HYDRA calculations of a 1.4 MJ $T_{R A D}=300 \mathrm{eV}$ ignition hohlraum and its plasma emulator. The plasma conditions are very similar: the larger hohlraum has slightly higher $T_{e}$ and correspondingly lower $n_{e}$.

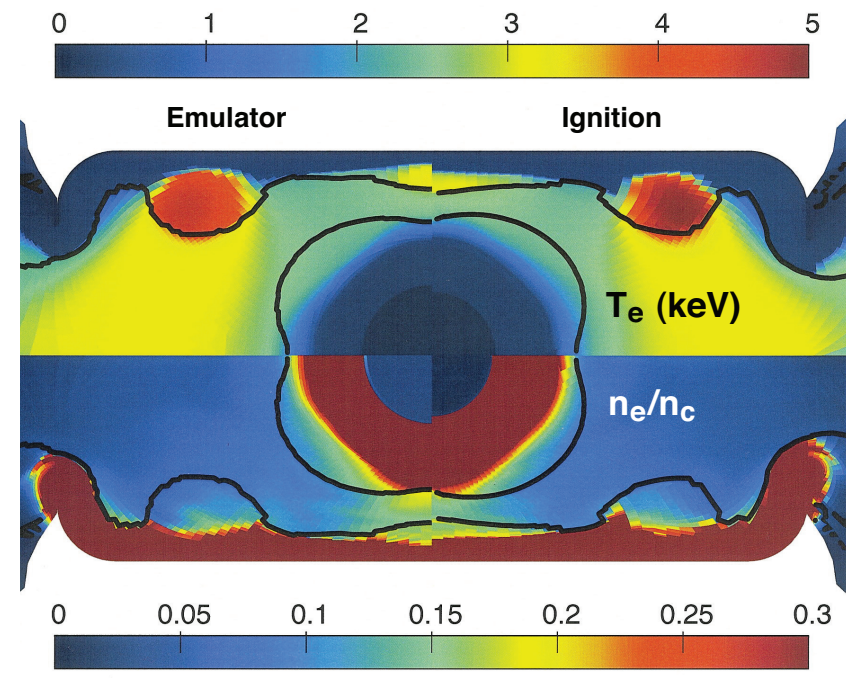

FIG. 4. (Color) Maps of electron density $n_{e} / n_{c}$ and temperature $T_{e}$ from HYDRA simulations of a 1.4 MJ, $T_{R A D}=300 \mathrm{eV}$ ignition hohlraum at time $=18 \mathrm{~ns}$ (see Fig. 2) and its sub-scale emulator. Time and space for the emulator have been scaled appropriately. We plot $T_{e}$ from 0 to $5 \mathrm{keV}$ and $n_{e} / n_{c}$ from 0 to 0.3 , as shown on the colorbars. The black contours show the boundaries between the hohlraum gas plasma and the ablated capsule and hohlraum wall plasmas.

\section{E. Campaign design}

The hohlraum energetics experiments performed on sub-scale emulator targets can be divided into four sub-campaigns:

1. Warm hohlraums filled with neopentane $\left(\mathrm{C}_{5} \mathrm{H}_{12}\right)$ gas, for diagnostic activation

2. Cryogenic hohlraums filled with $80 \% / 20 \%$ (atomic) hydrogen/helium

3. Cryogenic hohlraums filled with $100 \%$ helium 
4. Cryogenic hohlraums filled with $100 \%$ helium using the $700 \mathrm{~kJ}, T_{R A D}=300 \mathrm{eV}$ emulator pulse

The first three sub-campaigns used the $520 \mathrm{~kJ}, T_{R A D}=285 \mathrm{eV}$ emulator pulse. The third and fourth sub-campaigns described above include shots with a smaller laser focal spot in the interaction quads, to increase the laser intensity and gain level closer to the ignition gain level. All shots were performed with $180 \mathrm{GHz}$ of SSD bandwidth at $3 \omega$. We now describe the results of each of the four sub-campaigns.

\section{EXPERIMENTAL RESULTS}

\section{A. Warm hohlraums with hydrocarbon gas-fill}

The purpose of the two-shot warm hohlraum sub-campaign was to simultaneously field all of the target diagnostics described in section II A above without the additional complications of cryogenic operations. These diagnostics had been performance qualified on previous shots but had not operated simultaneously on one shot. In addition, we wanted to

begin the campaign with hydrocarbon-filled hohlraums, as we have had success predicting and controlling laser-plasma interactions in hydrocarbon-filled hohlraums on the OMEGA $\operatorname{laser}^{27-29}$.

The first shot returned data on all diagnostics. Backscattered light was low: $R_{S R S}=6$ $\%$ SRS reflectivity on the inner cone. On the outer cone, $R_{S R S}=0.5 \%$ and $R_{S B S}=1.4 \%$. Here, the reflectivity $R$ is reported as the total backscattered light energy divided by the laser energy delivered on that quad. The DANTE diagnostic measured a peak x-ray flux $F_{\max }=8000 \mathrm{GW} / \mathrm{sr}$, corresponding to an internal radiation temperature $T_{R A D} \approx 270 \mathrm{eV}$. The imploded core self-emission at the time of peak brightness is shown in Fig. 5(a.). We use a Legendre polynomial decomposition to quantify the shape of the core. We have found through simulations that the shape of contours around $20 \%$ of the image peak brightness tends to follow the shape of the inner surface of the dense shell. For this shot, the normalized amplitude of the $n=2$ Legendre polynomial $a_{2} / a_{0}=+0.09$ : The core is slightly prolate.

We used the second shot to demonstrate symmetry tuning by changing the power balance between the inner and outer cones. We define the inner cone fraction, $c f$, as the energy delivered by the inner cone beams divided by the total energy delivered over the fourth peak 
of the laser pulse. For the $520 \mathrm{~kJ}, T_{R A D}=285 \mathrm{eV}$ emulator pulse, the fourth pulse is from $9 \mathrm{~ns}$ to $11 \mathrm{~ns}$ (see Fig. 2). The baseline pulse has cone fraction $c f=0.33$. Using a tuning curve of $a_{2} / a_{0}$ vs. $c f$ from pre-shot HYDRA calculations, we adjusted the requested cone fraction to $c f=0.314$ for the second shot. As shown in Fig. 5(b.), the core of the second warm shot was very round, $a_{2} / a_{0}<0.02$.
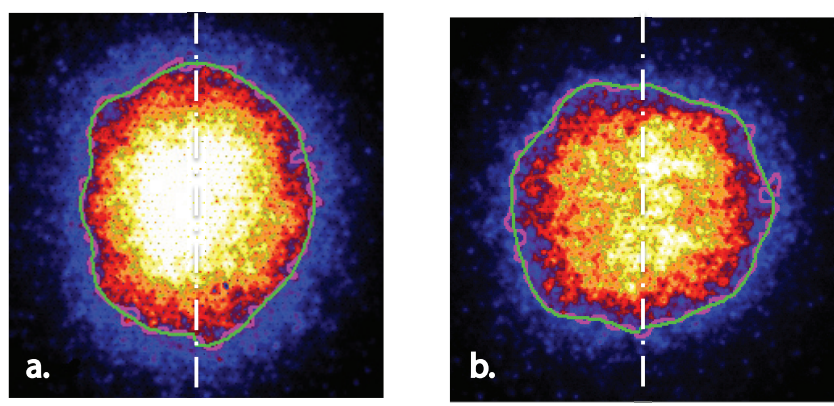

FIG. 5. (Color) Self-emission radiographs of imploded symcap cores taken with the GXD diagnostic for $\mathrm{C}_{5} \mathrm{H}_{12}$-filled hohlraums shot with a $520 \mathrm{~kJ} T_{R A D}=285 \mathrm{eV}$ emulator pulse. The requested laser inner-cone fraction was $c f=0.33$ for figure (a.) The subsequent shot (b.) was taken with $c f=0.314$, resulting in a round implosion.

\section{B. Cryogenic hohlraums with hydrogen/helium gas}

Following the success of the two warm gas-filled hohlraum shots, we fielded a series of shots using cryogenic hohlraums filled with an 80\% / $20 \%$ (by atom) hydrogen/helium mixture. These were the first successful laser-driven cryogenic gas-filled hohlraums ever fielded: to our knowledge, all previous attempts to shoot gas-filled cryogenic hohlraums on the NOVA and OMEGA laser systems encountered difficulties with condensation ${ }^{30}$. On the first shot, the measured SRS backscatter increased from $R_{S R S} \approx 6 \%$ to $R_{S R S} \approx 19 \%$ (Fig. 6 ). The peak x-ray flux measured by DANTE decreased from $F_{\max }=7800 \mathrm{GW} / \mathrm{sr}$ on the second warm shot to $F_{\max }=7200 \mathrm{GW} / \mathrm{sr}$.

\section{Cryogenic hohlraums with $100 \%$ helium gas fill}

The three-fold increase in SRS observed when we changed the hohlraum gas fill from $\mathrm{C}_{5} \mathrm{H}_{12}$ to $80 \%$ / $20 \%$ hydrogen/helium indicated that plasma composition strongly affects the SRS. This could be occurring for two reasons: The average ionization state $\left\langle Z^{*}\right\rangle$ affects 


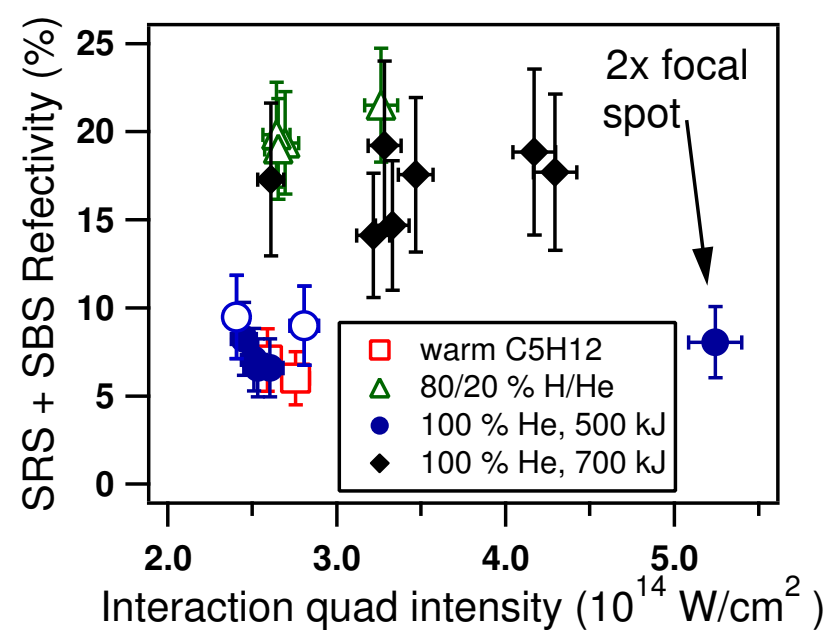

FIG. 6. (Color) Total (SRS+SBS) reflectivity vs. intensity on the inner-cone interaction (FABS/NBI) quad. The $100 \% \mathrm{He}, 520 \mathrm{~kJ}$ data set included a shot with $2 \times$ intensity phase plates, giving $I=5.2 \times 10^{14} \mathrm{~W} / \mathrm{cm}^{2}$. Shots with checkerboard polarization smoothing are denoted by solid symbols.

the inverse bremsstrahlung heating of the plasma by the laser. Thus, a higher $\left\langle Z^{*}\right\rangle$ gas-fill could increase the electron temperature $T_{e}$, decreasing $\mathrm{SRS}^{29}$. For a given electron density, a higher average atomic mass number $\langle A\rangle$ results in higher mass density $\rho$. This can affect the hydrodynamic expansion of the capsule ablator and the hohlraum wall into the hohlraum through the dynamic pressure $P \propto \rho v^{2}$, resulting in less compression of the gas plasma.

The highest $\left(\left\langle Z^{*}\right\rangle,\langle A\rangle\right)$ gas that can be used at the cryogenic temperatures needed for DT layering $(<19 \mathrm{~K})$ without condensing is pure helium. We decided to do a series of $520 \mathrm{~kJ}$ experiments with $100 \%$ helium gas fill, focused on measuring SRS backscatter under various beam-smoothing scenarios. The results of these shots are plotted versus laser intensity on the FABS/NBI quad in Fig. 6. Switching the hohlraum gas fill from 80\% / 20 $\%$ hydrogen/helium to $100 \%$ helium dropped the inner-cone SRS backscatter by half, from $R_{S R S} \approx 18 \%$ to $R_{S R S} \approx 9 \%$.

Polarization smoothing (PS) on NIF is accomplished by rotating the polarization in two of the four apertures in each quad by $90^{\circ}$, and then overlapping all four beams at the target ${ }^{6}$. During this sub-campaign, the PS configuration on the inner cone quads was changed. Initially, the two beams of a quad with equal polar angle had the same polarization. This was changed to a "checkerboard" configuration, in which diagonal beams in a quad have 
the same polarization. In Fig. 6, points before the PS change are denoted by open symbols. Switching the PS configuration slightly reduced the measured backscatter, so all subsequent shots used the checkerboard PS configuration. The PS configuration of the outer cone quads was not changed.

One of the six $100 \%$ helium shots had interaction phase plates inserted in the diagnosed FABS/NBI quads. These phase plates reduced the focal spot area by half, doubling the peak intensity. The resultant peak intensity $I=5.2 \times 10^{14} \mathrm{~W} / \mathrm{cm}^{2}$ is greater than the peak inner-cone intensity of the full-scale $T_{R A D}=300 \mathrm{eV}$ ignition hohlraum. The inner-cone SRS reflectivity remained below $10 \%$.

\section{D. $700 \mathrm{~kJ}, T_{R A D}=300 \mathrm{eV}$ emulator hohlraums}

Following the success (low $R_{S R S}$ ) of the $100 \%$ helium gas-fill with the $520 \mathrm{~kJ}, T_{R A D}=285$ $\mathrm{eV}$ emulator laser pulse, we explored the longer, higher power $700 \mathrm{~kJ}, T_{R A D}=300 \mathrm{eV}$ emulator pulse suitable for a $\mathrm{CH}$ ablator capsule (see Fig.2). As shown in Fig. 6, the innercone SRS reflectivity for these shots varied from 15-21\%. Note that SBS scattering on the inner cone was negligible $(\ll 1 \%)$ on all the gas-filled hohlraum shots with initial gas density $n_{e}=0.045 n_{c}$. One $700 \mathrm{~kJ}, T_{R A D}=300 \mathrm{eV}$ emulator shot shown in Fig. 6 was fielded with an initial gas density of $n_{e}=0.0225 n_{c}$. This shot produced $R_{S R S}=15 \%$ and $R_{S B S}=4 \%$ at an intensity $I \approx 4 \times 10^{14} \mathrm{~W} / \mathrm{cm}^{2}$.

\section{E. Outer cone backscatter}

The measured backscatter on the outer cone FABS/NBI quad was consistently small, $R_{S R S}+R_{S B S} \lesssim 6 \%$. The total outer cone backscatter reflectivity is shown in Fig. 7 . The experimental database includes two $100 \%$ helium shot with $2 \times$ intensity phase plates on the outer interaction cone and a shot with a pure gold inner hohlraum wall, i.e., no thin $\mathrm{AuB}$ layer. Neither change increased reflectivity above $2 \%$. Note that the peak intensities of the two shots with the $2 \times$ intensity phase plate, $I=1.3 \times 10^{15} \mathrm{~W} / \mathrm{cm}^{2}$ and $I=1.7 \times 10^{15}$ $\mathrm{W} / \mathrm{cm}^{2}$, are greater than the peak outer-cone intensity of the full-scale $T_{R A D}=300 \mathrm{eV}$ ignition hohlraum. All of the shots shown with a $100 \%$ helium gas fill produced $\leq 2 \%$ outer-cone reflectivity. This is an important result: two-thirds of the power and energy 
available on the NIF laser is generated by the outer cone beams. Thus, the total backscatter reflectivity for the hohlraum is given by $R_{\text {tot }} \approx \frac{1}{3} R_{\text {inner }}+\frac{2}{3} R_{\text {outer }} \lesssim 7 \%$ for the shots shown in Figs. 6 and 7 .

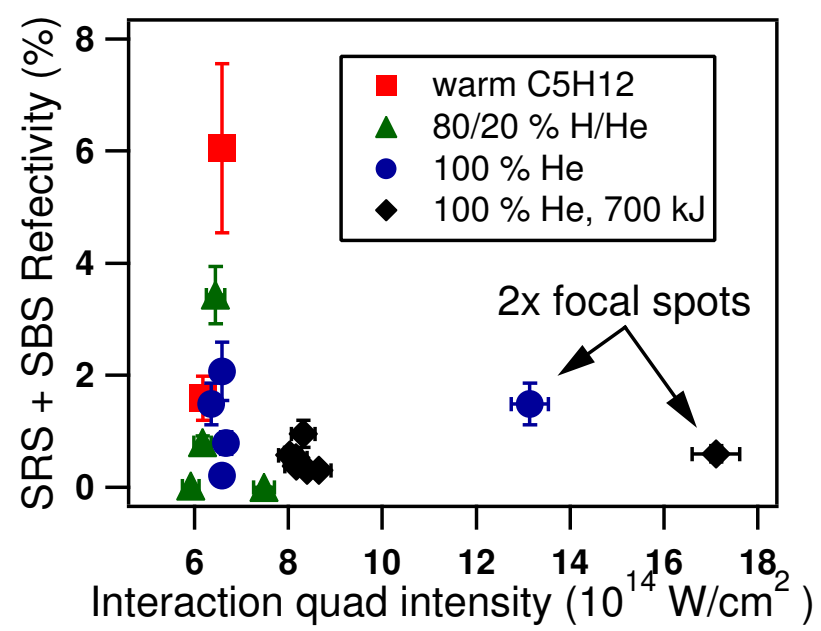

FIG. 7. (Color) Total (SBS + SRS) reflectivity vs. intensity on the outer-cone interaction (FABS/NBI) quad. The $100 \% \mathrm{He}, 520 \mathrm{~kJ}$ and $700 \mathrm{~kJ}$ data sets include shots with $2 \times$ intensity phase plates, giving $I=1.3 \times 10^{15} \mathrm{~W} / \mathrm{cm}^{2}$ and $I=1.7 \times 10^{15} \mathrm{~W} / \mathrm{cm}^{2}$, respectively.

\section{HOHLRAUM X-RAY DRIVE PERFORMANCE}

\section{A. Radiation hydrodynamics simulations}

To this point, we have provided evidence that the energetics campaign has met its goal of establishing low backscatter (total backscattered power $R<10 \%$ ). Determining if we have met the x-ray drive goal requires detailed comparison of the hohlraum performance data with design code calculations. We compare experimental data to post-shot simulations starting with initial conditions that are as close as possible to the real experimental conditions. Target data is taken from detailed fabrication metrology of all hohlraum and capsule dimensions, compositions, and densities. Laser pulse input is taken from NIF's laser power and energy diagnostics. Backscatter is accounted for by removing laser power from the input sources. We calculate the instantaneous reflectivity $R(t)$ measured by FABS and NBI on a single quad:

$$
R(t)=P_{S R S}(t) / P_{\text {laser }}(t)
$$


We then apply that reflectivity to all of the quads in that cone:

$$
\begin{gathered}
P_{\text {inner }}=\sum_{i} P_{23.5}\left(1-R_{\text {inner }}\right)+\sum_{i} P_{30}\left(1-R_{\text {inner }}\right), \\
P_{\text {outer }}=\sum_{i} P_{44.5}\left(1-R_{\text {outer }}\right)+\sum_{i} P_{50}\left(1-R_{\text {outer }}\right) .
\end{gathered}
$$

We believe this is a conservative assumption: the laser intensities of the $23.5^{\circ}$ and $44.5^{\circ}$ quads are lower than their partners on the $30^{\circ}$ and $50^{\circ}$ quads because the focal spots are larger.

We generate synthetic x-ray data for comparison to experiments. Straight rays, each representing a pixel in a virtual detector, are traced through the simulation mesh along the diagnostic line-of-sight. The density, temperature, opacity, and emissivity are extracted from each zone, as well as the ray path-length through the zone. These data are used to integrate a radiation transport equation along each ray, generating the spectral intensity (e.g., $\mathrm{W} / \mathrm{cm}^{2} / \mathrm{keV} / \mathrm{sr}$ ) of each virtual pixel. To simulate a non-imaging diagnostic such as DANTE, we integrate the spectral intensity over area and photon energy, providing the total flux (power per unit solid angle) as a function of time.

\section{B. X-ray flux measurements}

We summarize the x-ray drive performance of the experiments relative to the ICF code predictions in Fig. 8. This figure shows the post-shot simulated flux vs. the peak x-ray flux measured by the DANTE diagnostic for all of the gas-filled hohlraum shots described above. In general, the measured flux is slightly higher than the calculations, but the calculated flux is within $\pm 10 \%$ of the data. The $\mathrm{x}$-error bars represents the $\pm 5 \%$ absolute uncertainty of DANTE based on the roll-up of the calibration uncertainties of its many components. This result is generally in line with previous comparisons between LASNEX and experiments on the NOVA and OMEGA laser facilities ${ }^{2,14}$ and with early NIF experiments ${ }^{11}$. These data suggest that LASNEX and HYDRA calculations using the point-design model are conservative with respect to x-ray flux. 


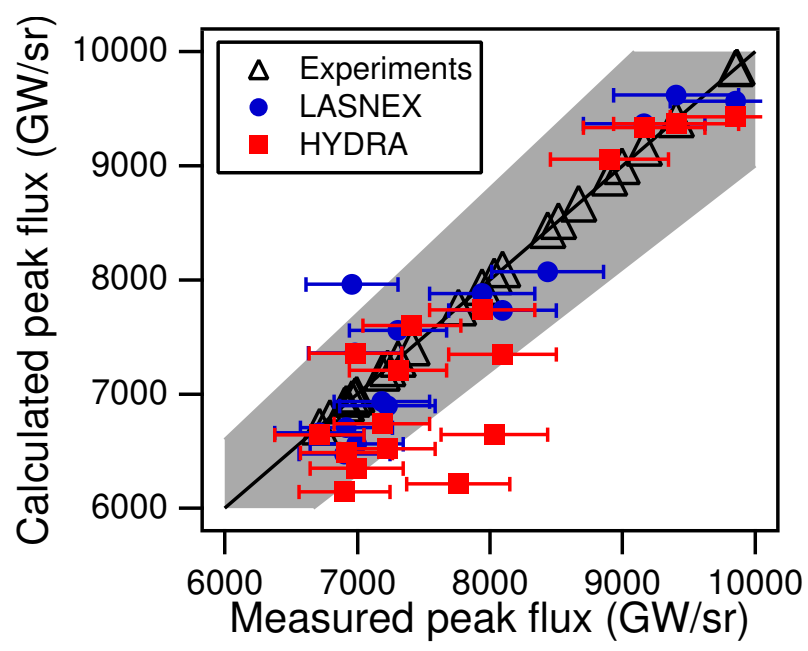

FIG. 8. (Color) Simulated peak x-ray flux from rad-hydro calculations vs. experimental peak DANTE flux. The gray band is $\pm 10 \%$ in flux. In this type of plot, the experimental data points $(\triangle)$ lie on the line $y=x$.

\section{X-ray bang time}

One way to cross-check the x-ray flux data from DANTE is to compare the calculated and measured times of peak capsule emission. This "x-ray bang-time" is an integral measure of the x-ray power absorbed by the capsule ablator, so we expect bang time and hohlraum x-ray flux to be strongly correlated; however, the bang-time also depends on physical parameters unrelated to the hohlraum radiation environment, i.e., the opacity and equation of state of the capsule. Uncertainty in these physical parameters reduces the utility of bang time as an absolute measure of x-ray flux.

The calculated and measured x-ray bang times are compared in Fig. 9. Note that bang time data are plotted against DANTE flux data, whereas simulated bang-times are plotted against simulated DANTE flux. When we plot x-ray bang time vs. peak x-ray flux, all of the $520 \mathrm{~kJ}$ hohlraum data collapse onto one line: bang-time correlates with x-ray flux, as expected. Indeed, the bang time vs. flux slope is very similar between the data and the simulations. At a given x-ray flux, the experimental bang time is $\approx 300 \mathrm{ps}$ later than the calculations. These data suggest that the hohlraum x-rays are not coupling to the capsule ablator as expected in the ICF design codes. Note that this discrepancy is in addition to the $5-10 \%$ discrepancy in flux shown in Fig. 8. This will be the subject of further experimental 
and modeling efforts.

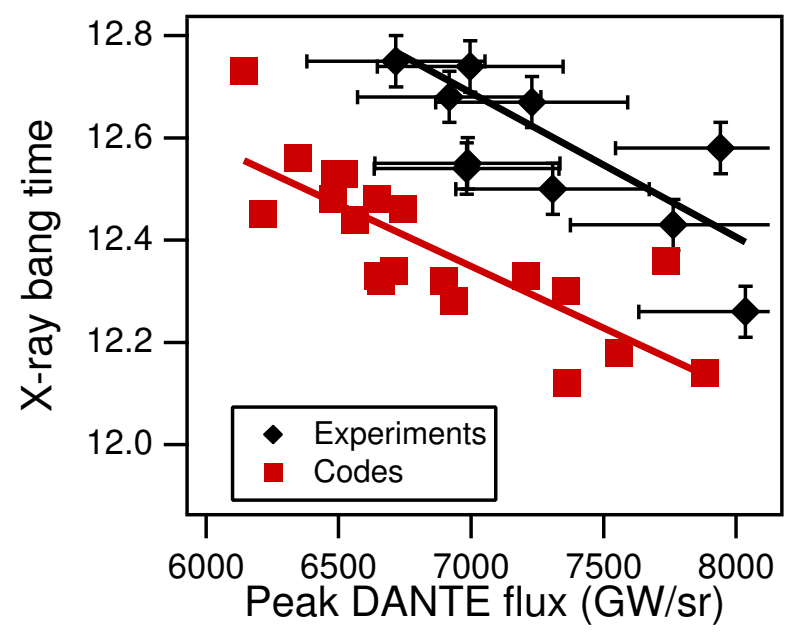

FIG. 9. (Color) Experimental and simulated x-ray bang time vs. peak DANTE flux. Note that experimental bang times are plotted vs. experimental x-ray flux, whereas simulated bang times are plotted vs. simulated x-ray flux.

\section{CONCLUSIONS}

Based on the results of the first hohlraum energetics experiments on NIF, we believe that we are on the path to a $T_{R A D}=300 \mathrm{eV}$ ignition hohlraum design that uses 1.2-1.5 MJ of laser energy. We have demonstrated reduction of SRS backscatter losses by filling the hohlraums with pure helium rather than a hydrogen/helium mixture. Total backscatter levels are below $10 \%$ for helium-filled hohlraums, with outer-cone backscatter $\lesssim 2 \%$. We also find that the hot electron fraction $f_{\text {hot }}=E_{\text {hot }} / E_{\text {laser }}$ is below $2 \%$ on all shots. We have shown that peak x-ray flux measurements are close to ICF design code descriptions. X-ray bang time data show that capsule velocity varies with hohlraum radiation temperature as predicted by the design codes, although the offset between measured and calculated bang-times must be investigated further. Together, these results point towards 1.2 -1.5 MJ hohlraums that can meet ignition specifications at $T_{R A D}=300 \mathrm{eV}$. 


\section{ACKNOWLEDGMENTS}

We would like to acknowledge the efforts of the NIF operations, laser performance, target diagnostics, and target fabrication teams. This work performed under the auspices of the U. S. Department of Energy by Lawrence Livermore National Laboratory under Contract DE-AC52-07NA27344 and by by Los Alamos National Laboratory under contract DE-AC5206NA25396.

\section{REFERENCES}

${ }^{1}$ E. Moses, R. Boyd, B. Remington, C. Keane, and R. Al-Ayat, Phys. Plasmas 16, 041006 (13 pp.) (2009).

${ }^{2}$ J. Lindl, P. Amendt, R. Berger, S. Glendinning, S. Glenzer, S. Haan, R. Kauffman, O. Landen, and L. Suter, Phys. Plasmas 11, 339 (2004).

${ }^{3}$ P. Michel, L. Divol, E. Williams, S. Weber, C. Thomas, D. Callahan, S. Haan, J. Salmonson, S. Dixit, D. Hinkel, M. Edwards, B. MacGowan, J. Lindl, S. Glenzer, and L. Suter, Phys. Rev. Lett. 102, 025004 (4 pp.) (2009).

${ }^{4}$ P. Michel, S. H. Glenzer, L. Divol, D. K. Bradley, D. Callahan, S. Dixit, S. Glenn, D. Hinkel, R. K. Kirkwood, J. L. Kline, W. L. Kruer, G. A. Kyrala, S. Le Pape, N. B. Meezan, R. Town, K. Widmann, E. A. Williams, B. J. MacGowan, J. L. Lindl, L. J. Suter, Symmetry tuning via controlled crossed-beam energy transfer on the National Ignition Facility, submitted to Phys. Plasmas, (2009).

${ }^{5}$ S. H. Glenzer, B. J. MacGowan, P. Michel, N. B. Meezan, L. J. Suter, S. N. Dixit, J. L. Kline, G. A. Kyrala, D. K. Bradley, D. A. Callahan, E. L. Dewald, L. Divol, E. Dzenitis, M. J. Edwards, A. V. Hamza, C. A. Haynam, D. E. Hinkel, D. H. Kalantar, J. D. Kilkenny, O. L. Landen, J. D. Lindl, S. LePape, J. D. Moody, A. Nikroo, T. Parham, M. B. Schneider, R. P. J. Town, P. Wegner, K. Widmann, P. Whitman, B. K. F. Young, B. Van Wonterghem, L. J. Atherton, and E. I. Moses, Science, 28 January 2010 (10.1126/science.1185634)

${ }^{6}$ C. A. Haynam, P. J. Wegner, J. M. Auerbach, M. W. Bowers, S. N. Dixit, G. V. Erbert, G. M. Heestand, M. A. Henesian, M. R. Hermann, K. S. Jancaitis, K. R. Manes, C. D. Marshall, N. C. Mehta, J. Menapace, E. Moses, J. R. Murray, M. C. Nostrand, C. D. Orth, R. Patterson, R. A. Sacks, M. J. Shaw, M. Spaeth, S. B. Sutton, W. H. Williams, C. C. 
Widmayer, R. K. White, S. T. Yang, and B. M. V. Wonterghem, Appl. Opt. 46, 3276 (2007).

${ }^{7}$ A. Mackinnon, C. Niemann, K. Piston, G. Holtmeier, T. McCarville, G. Jones, I. Reinbachs, R. Costa, J. Celeste, R. Griffith, R. Kirkwood, B. MacGowan, and S. Glenzer, Rev. Sci. Instrum. 77, 10E529 (2006). This reference describes an older version of the NBI diagnostic.

${ }^{8}$ P. Neumayer, C. Sorce, D. Froula, L. Divol, V. Rekow, K. Loughman, R. Knight, S. Glenzer, R. Bahr, and W. Seka, Rev. Sci. Instrum. 79, 10F548 (3 pp.) (2008).

${ }^{9}$ M. Landon, J. Koch, S. Alvarez, P. Bell, F. Lee, and J. Moody, Rev. Sci. Instrum. 72, 698 (2001),

${ }^{10}$ E. L. Dewald, K. M. Campbell, R. E. Turner, J. P. Holder, O. L. Landen, S. H. Glenzer, R. L. Kauffman, L. J. Suter, M. Landon, M. Rhodes, and D. Lee, Rev. Sci. Instrum. 75, 3759 (2004).

${ }^{11}$ E. Dewald, O. Landen, L. Suter, J. Schein, J. Holder, K. Campbell, S. Glenzer, J. McDonald, C. Niemann, A. Mackinnon, M. Schneider, C. Haynam, D. Hinkel, and B. Hammel Phys. Plasmas 13, 56315 (2006).

${ }^{12}$ J. McDonald, L. Suter, O. Landen, J. Foster, J. Celeste, J. Holder, E. Dewald, M. Schneider, D. Hinkel, R. Kauffman, L. Atherton, R. Bonanno, S. Dixit, D. Eder, C. Haynam, D. Kalantar, A. Koniges, F. Lee, B. MacGowan, K. Manes, D. Munro, J. Murray, M. Shaw, R. Stevenson, T. Parham, B. Van Wonterghem, R. Wallace, P. Wegner, P. Whitman, B. Young, B. Hammel, and E. Moses Phys. Plasmas 13, 32703 (2006).

${ }^{13}$ G. Zimmerman and W. Kruer, Comments on Plasma Physics and Controlled Fusion 2, 51 (1975).

${ }^{14}$ J. Lindl, Phys. Plasmas 2, 3933 (1995).

${ }^{15}$ M. M. Marinak, G. D. Kerbel, N. A. Gentile, O. Jones, D. Munro, S. Pollaine, T. R. Dittrich, and S. W. Haan, Phys. Plasmas 8, 2275 (2001).

${ }^{16} \mathrm{~W}$. A. Lokke and W. H. Grasberger, XSNQ-U: A non-LTE emission and absorption coefficient subroutine (1977), See National Technical Information Service Document No. UCRL52276. Copies may be ordered from the National Technical Information Service, Springfield, VA 22161.

${ }^{17}$ A. Djaoui and S. Rose, J. Phys. B 25, 2745 (1992). The average-atom NLTE model described in this paper is very similar to XSN. 
${ }^{18}$ R. More, K. Warren, D. Young, and G. Zimmerman, Phys. Fluids 31, 3059 (1988).

${ }^{19}$ D. Callahan, D. Hinkel, R. Berger, L. Divol, S. Dixit, M. Edwards, S. Haan, O. Jones, J. Lindl, N. Meezan, P. Michel, S. Pollaine, L. Suter, and R. Town Journal of Physics: Conference Series 112, 022021 (4 pp.) (2008).

${ }^{20}$ S. Haan, D. Callahan, M. Edwards, B. Hammel, D. Ho, O. Jones, J. Lindl, B. MacGowan, M. Marinak, D. Munro, S. Pollaine, J. Salmonson, B. Spears, and L. Suter Fusion Science and Technology 55, 227 (2009).

${ }^{21}$ P. Neumayer, R. Berger, L. Divol, D. Froula, R. London, B. MacGowan, N. Meezan, J. Ross, C. Sorce, L. Suter, and S. Glenzer Phys. Rev. Lett. 100, 105001 (2008).

${ }^{22}$ P. Neumayer, R. Berger, D. Callahan, L. Divol, D. Froula, R. London, B. MacGowan, N. Meezan, P. Michel, J. Ross, C. Sorce, K. Widmann, L. Suter, and S. Glenzer Phys. Plasmas 15, 056307 (2008).

${ }^{23}$ S. Haan, P. Amendt, T. Dittrich, B. Hammel, S. Hatchett, M. Herrmann, O. Hurricane, O. Jones, J. Lindl, M. Marinak, D. Munro, S. Pollaine, J. Salmonson, G. Strobel, and L. Suter, Nuclear Fusion 44, S171 (2004).

${ }^{24}$ A. Nobile, A. Nikroo, R. Cook, J. Cooley, D. Alexander, R. Hackenberg, C. Necker, R. Dickerson, J. Kilkenny, T. Bernat, K. Chen, H. Xu, R. Stephens, H. Huang, S. Haan, A. Forsman, L. Atherton, S. Letts, M. Bono, and D. Wilson, Laser and Particle Beams 24, 567 (2006).

${ }^{25}$ D. W. Forslund, J. M. Kindel, and E. L. Lindman, Phys. Fluids 18, 1017 (1975).

${ }^{26}$ J. F. Drake, P. K. Kaw, Y. C. Lee, G. Schmid, C. S. Liu, and M. N. Rosenbluth, Phys. Fluids 17, 778 (1974).

${ }^{27}$ L. Divol, R. Berger, N. Meezan, D. Froula, S. Dixit, P. Michel, R. London, D. Strozzi, J. Ross, E. Williams, B. Still, L. Suter, and S. Glenzer, Phys. Plasmas 15, 056313 (2008). ${ }^{28}$ D. Froula, L. Divol, R. Berger, R. London, N. Meezan, D. Strozzi, P. Neumayer, J. Ross, S. Stagnitto, L. Suter, and S. Glenzer, Phys. Rev. Lett. 101, 115002 (4 pp.) (2008).

${ }^{29}$ D. Froula, L. Divol, R. London, R. Berger, T. Doppner, N. Meezan, J. Ross, L. Suter, C. Sorce, and S. Glenzer, Phys. Rev. Lett. 103, 045006 (4 pp.) (2009).

${ }^{30}$ T. R. Boehly, R. E. Olson, P. M. Celliers, D. H. Munro, W. Seka, O. L. Landen, G. W. Collins, L. J. Suter, T. C. Sangster, and D. D. Meyerhofer, "The effect of condensates and inner coatings on the performance of vacuum hohlraum targets," submitted to Phys. Plasmas (2010) 